OPEN ACCESS

Edited by:

Stephen Fairclough, Liverpool John Moores University, United Kingdom

Reviewed by:

Chun-Hao Wang,

National Cheng Kung University,

Taiwan

Valentina Bianco

Santa Lucia Foundation (IRCCS), Italy

${ }^{*}$ Correspondence:

Chetwyn C. H. Chan

Chetwyn.Chan@polyu.edu.hk

Specialty section:

This article was submitted to

Motor Neuroscience,

a section of the journal

Frontiers in Human Neuroscience

Received: 05 September 2019

Accepted: 29 October 2019

Published: 14 November 2019

Citation:

Yu Q, Chau BKH, Lam BYH,

Wong AWK, Peng J and Chan $\mathrm{CCH}$ (2019) Neural Processes of Proactive and Reactive Controls Modulated by

Motor-Skill Experiences.

Front. Hum. Neurosci. 13:404. doi: 10.3389/fnhum.2019.00404

\section{Neural Processes of Proactive and Reactive Controls Modulated by Motor-Skill Experiences}

\author{
Qiuhua Yu',2, Bolton K. H. Chau ${ }^{2}$, Bess Y. H. Lam², Alex W. K. Wong ${ }^{3,4}$, Jiaxin Peng ${ }^{2,5}$ and \\ Chetwyn C. H. Chan ${ }^{2,6 *}$
}

\begin{abstract}
${ }^{1}$ Department of Rehabilitation Medicine, The First Affiliated Hospital, Sun Yat-sen University, Guangzhou, China, ${ }^{2}$ Applied Cognitive Neuroscience Laboratory, Department of Rehabilitation Sciences, The Hong Kong Polytechnic University, Hong Kong, China, ${ }^{3}$ Program in Occupational Therapy, Washington University School of Medicine, St. Louis, MO, United States, ${ }^{4}$ Department of Neurology, Washington University School of Medicine, St. Louis, MO, United States, ${ }^{5}$ Department of Education, Shaoguan University, Shaoguan, China, ${ }^{6}$ University Research Facility in Behavioral and Systems Neuroscience, The Hong Kong Polytechnic University, Hong Kong, China
\end{abstract}

This study investigated the experience of open and closed motor skills on modulating proactive and reactive control processes in task switching. Fifty-four participants who were open-skilled $(n=18)$ or closed-skilled athletes $(n=18)$ or non-athletic adults $(n=18)$ completed a cued task-switching paradigm task. This task tapped into proactive or reactive controls of executive functions under different validity conditions. Electroencephalograms of the participants were captured during the task. In the 100\% validity condition, the open-skilled participants showed significantly lower switch cost of response time than the closed-skilled and control participants. Results showed that the open-skilled participants had less positive-going parietal cue-locked P3 in the switch than repeat trials. Participants in the control group showed more positive-going cuelocked P3 in the switch than repeat trials, whereas the closed-skilled participants had no significant differences between the two types of trials. In the $50 \%$ validity condition, the open- and closed-skilled participants had less switch cost of response time than the control participants. Participants in the open- and closed-skilled groups showed less positive-going parietal stimulus-locked P3 in the switch than repeat trials, which was not the case for those in the control group. Our findings confirm the dissociation between proactive and reactive controls in relation to their modulations by the different motor-skill experiences. Both proactive and reactive controls of executive functions could be strengthened by exposing individuals to anticipatory or non-anticipatory enriched environments, suggesting proactive and reactive controls involved in motor-skill development seem to be transferable to domain-general executive functions.

Keywords: proactive control, reactive control, task switching, ERP, motor skills

\section{INTRODUCTION}

A high level of motor skills has been associated with improved executive functions. Sports are physical activities that require high levels of motor skills. Individuals who engaged in fencing (Chan et al., 2011), baseball (Kida et al., 2005), and soccer were reported to have better executive functions than the controls (Verburgh et al., 2014). Researchers have suggested that the enhancement in 
executive functions could be related to the neural plasticity brought about by the long-term aerobic fitness and cognitive trainings involved in these sports (Voss et al., 2010; Chan et al., 2011). Common features of the physical activities described above are playing facing opponents and in changing external environments, which demand open motor skills. Open motor skills involve generation of physical responses to dynamically and externally paced environment (Wang et al., 2013a; Yu et al., 2017). Contrary to open motor skills is closed motor skills, which requires participants to generate responses that are relatively consistent, stationary, and self-paced (Wang et al., 2013a; Yu et al., 2017). The typical physical activities involving closed motor skills are swimming, and track and field. In view of the differences between open and closed motor skills, it is intuitive that participants of "closed" physical activities would have gained lower level of executive functions than those of "open" physical activities. For instance, open-skilled participants were revealed to have higher levels of inhibitory control than the closedskilled counterparts (Yamashiro et al., 2015). Nevertheless, in an earlier behavioral study, we reported that, by employing a dual cognitive control model for executive functions (Chevalier et al., 2015; Tarantino et al., 2016), both the open- and closedskilled participants showed significantly higher levels of reactive control of executive functions than the controls ( $\mathrm{Yu}$ et al., 2017). The differences between the two experimental groups are in the proactive versus reactive control. In this paper, we aimed to employ electroencephalogram to understand the neural mechanisms underlying how different types of motor skills would associate with proactive or reactive controls among participants engaging in physical activities.

Proactive control is an early selection process, which can optimally bias attention, perception, and action systems in a goal-driven manner (Braver, 2012). Information selected early in the process is to be deployed before the response-demanding event occurs. In contrast, reactive control is to resolve the interference imperatively after the response-demanding event appears (Braver, 2012). Physical activities dominated by open motor skills involve predictions of outcomes upon the actions of opponents and teammates for producing rapid and accurate responses (Jin et al., 2011; Abreu et al., 2012; Yu et al., 2016). These cognitive processes are comparable to those described in proactive control. In contrast, the physical activities dominated by closed motor skills less involve the prediction of actions of others before giving the responses. In addition, open motor skills require the participants to rapidly inhibit inappropriate actions, and switch from an intended movement to an appropriate one in an unpredictable environment (Taddei et al., 2012; Yu et al., 2017). The imperative inhibition and switching process are comparable to those described in reactive control. Tsai and Wang (2015) explored the effects of open- (e.g., badminton and table tennis) or closed-skilled (e.g., jogging and swimming) training in the reactive control of task switching for elderly subjects. Their results showed that open-skilled group had larger P3 amplitude in switch condition than closed-skilled and control groups, but had comparable P3 amplitude in repeat condition with the other two groups. All the studies revealed employed a unidimensional perspective of executive control. The results are that open-skilled groups had higher level of executive functions in reactive control associated with enhanced P3 than closed-skilled groups. No study has been conducted to explore and explain the possible gains in different time processes of executive functions differentially in the open- and closed-skilled groups. The dual cognitive control model of executive function offers a theoretical basis for addressing the potential differentiation in the cognitive gains due to the engagement in these physical activities.

Neural processes related to proactive and reactive controls can be examined by using a cued task-switching paradigm with electroencephalogram (EEG). The cued task-switching paradigm involves participants predicting a switch of task rule based on the information embedded in the cue and subsequently giving a response according to the new rule. The task cue can be fully predictive ( $100 \%$ validity) or fully non-predictive (50\% validity), which makes possible elicitation of the eventrelated potentials (ERPs) for reflecting the proactive or reactive control processes, respectively. The common ERPs associated with proactive control in the task-switching paradigm reported are the parietally distributed P3 elicited by the cue (called cuelocked P3) (Gajewski and Falkenstein, 2011; Tarantino et al., 2016) and the frontocentrally distributed contingent negative variant (CNV) (Tarantino et al., 2016). In contrast, the frontally distributed N2 (Hsieh and $\mathrm{Wu}, 2011$ ) and parietally distributed P3 (called stimulus-locked P3) (Scisco et al., 2008; Tarantino et al., 2016) elicited by the stimulus were reported to associate with the reactive control in task switching. The cue-locked P3 can be identified within the 300-600 ms time-window after the appearance of a predictive cue (West et al., 2012; Tarantino et al., 2016). This component was suggested to reflect task reconfiguration - anticipatory updating of task goals and/or action rules in working memory (Nicholson et al., 2006; Gajewski and Falkenstein, 2011). The CNV is a slow wave elicited prior to the onset of the target stimulus (Funderud et al., 2013). It reflects anticipatory attention and motor preparation for the upcoming target stimulus (Funderud et al., 2013; Grane et al., 2016). Thus, the amplitude of $\mathrm{CNV}$ could be modulated by the responserelated parameters embedded in the task cue (Scheibe et al., 2009; Linssen et al., 2013), e.g., the cue validity. Previous studies also showed that Bereitschaftspotential (BP), comparable to CNV, was more negative-going in athletes than non-athletes (Bianco et al., 2017a,b). This finding suggested that the athletes would have better motor preparation than the non-athletes. However, Wang et al. (2013b) did not reveal significant differences in motor preparation between the open- and closed-skilled players.

The N2 component has been employed as a marker reflecting reactive control - suppression of conflict responses (Rushworth et al., 2002; Hsieh and Wu, 2011). More negative-going frontal N2 was shown to associate with the switching to a new response set. The stimulus-locked P3 can be identified after the appearance of a response-demanding stimulus (Swainson et al., 2006; Tarantino et al., 2016). In the predictive cue condition, the stimulus-locked P3 accounts for stimulus-response set implementation (Jamadar et al., 2010; Gajewski and Falkenstein, 2011; Tarantino et al., 2016) or task-specific evaluation of a target stimulus (Swainson et al., 2006). The amplitude difference of stimulus-locked P3 between switch and repeat trials was negatively related to the switch cost 
of the response time when the cue was predictive (Li et al., 2012), suggesting that stimulus-locked $\mathrm{P} 3$ in reactive control was related to the performance in task switching. In the non-predictive cue condition, stimulus-locked P3 is associated with updating of the task goal or task rules (Hillman et al., 2006; Scisco et al., 2008). It was more positive-going in the switch than repeat trials, because more attentional resources required for subsequent memory updating in reactive control (Hillman et al., 2006; Scisco et al., 2008). However, Kamijo and Takeda (2010) reported intensive experience of physical training, regardless of type of sport, showed less positive stimulus-locked P3 in the switch than repeat trials in an alternating-runs switching paradigm. The reason was likely that these studies showed differences in the task difficulties, which P3 component was sensitive to Kamijo and Takeda (2010).

In this study, a cued task-switching task was employed for eliciting the proactive and reactive control processes modulated by the participants with experience of open- or closed-skilled physical activities. As the participants had received intensive training of two types of motor skills, we hypothesized that in the trials with predictive cues (100\% validity), the openskilled participants would show fewer positive differences in the between-trial (switch verse repeat) cue-locked P3 compared with the closed-skilled participants due to employing more anticipation in the open-skilled training. It was also hypothesized that in the trials with non-predictive cues (50\% validity), the open-skilled participants would show fewer positive differences in the between-trial stimulus-locked P3 than the closedskilled and control ones due to the imperative switch in the unpredictable environment. More negative-going $\mathrm{CNV}$ in the open- and closed-skilled than controls participants were anticipated due to better preparation in the former two groups. Comparable N2 amplitudes were anticipated in the open- and closed-skilled participants. The performances in the neural processes of the $75 \%$ validity condition would be between those of the 100 and $50 \%$ validity conditions.

\section{MATERIALS AND METHODS}

\section{Participants}

Fifty-four university students were recruited via convenience sampling. Among them, 18 (8 females and 10 males) were members of the university badminton team (open-skilled group), 18 (7 females and 11 males) were members of the university track and field team (closed-skilled group), and 18 (9 females and 9 males) declared they had not engaged in any professional or amateur sport (control group). The selection of badminton and track and field athletes as the open- and closed-skilled participants was made reference to those recruited in Wang and Tu (2017) and Wang et al. (2017). The results obtained would have more meaningful comparisons with those reported by Wang and Tu (2017) and Wang et al. (2017). Participants in each group had matched age and education levels (Table 1). The participants of the open- and closed-skilled groups had five or more years for professional motor skill practices. Each athlete had won prizes in open competitions and had no regular training in other sports. The levels of skill competences (in terms of winning international/local sport awards) were comparable between two groups ( $n=2 / 16$ for open-skilled versus $n=3 / 15$ for closed-skilled). All of the participants were right-handed with normal or corrected-to-normal visual acuity, and had no history of neurological or cardiovascular disorders. Participants were not on regular medication. The participant's cardiorespiratory fitness was assessed by the Queen's College step test, which had been introduced in Yu et al.'s (2017). Ethical approval of this study was granted by the Departmental Research Committee of The Hong Kong Polytechnic University. Written informed consent was obtained from the participants before commencing the experiment for data collection.

\section{Experimental Task}

This study used a cued task-switching paradigm to manipulate the proactive and reactive controls. Details of the task design were described in Yu et al. (2017). The time course of one typical trial is summarized in Figure 1. A trial began with presentation of a task cue $(4 \mathrm{~cm} \times 4 \mathrm{~cm})$ at the center of the screen for $1500 \mathrm{~ms}$. Then the task cue was replaced by a target stimulus $(4 \mathrm{~cm} \times 4 \mathrm{~cm})$. Upon presentation of the target stimulus, the participant was asked to give a two-key sequential response correctly as soon as possible within $3000 \mathrm{~ms}$. The next trial began once the response from the participant was registered. Next, a blank interval of $1000 \mathrm{~ms}$ appeared before the onset of the next trial.

In this paradigm, proactive and reactive controls were manipulated by means of cue validities. Three cue validities were used: 100,75 , and $50 \%$. A $100 \%$ valid cue appeared as a solid square $\mathbf{\square}$ (or diamond $\boldsymbol{\bullet}$ ), a $75 \%$ valid cue appeared as a hollow square (or diamond 0 ), and a $50 \%$ valid cue appeared (as a solid star $\bullet$ ). The participants were asked to prepare the response selection rules based on the cue (except for a 50\% valid cue). A $100 \%$ valid cue meant the rule sets conveyed in the cue would be the same as those that appeared in the target stimulus. In this case, the participant could prepare to repeat the same task rule as the previous trial or switch to a new task rule based on the rule set conveyed in the cue. Thus, a 100\% valid cue would elicit more proactive but fewer reactive control processes. A $50 \%$ valid cue meant that no information on the task sets in the subsequent response was provided. In such an ambivalent situation, the participant could not give a specific preparation for the response. The participant could repeat the same task rule or switch to a new task rule based on the target stimulus. It was expected that a 50\% valid cue would elicit reactive rather than proactive control processes. A 75\% valid cue was expected to elicit mental processes that were a combination of those in the 50 and $100 \%$ validity conditions. A digit (1 or 2) that appeared inside the shape (a square or diamond) formed the target stimulus (Figure 1). Two sets of response selection rules were used. Each rule involved two sets of two-key sequential responses delivered by the target stimulus with the same shape (square or diamond). For instance, one response selection rule was that a square with digit " 1 " was for the participant to press the " $\mathrm{z}$ " and then " $\mathrm{n}$ " keys on the keyboard, and a square with digit " 2 " was " $x$ " and then " $m$ "; the other response selection rule was that a diamond with digit " 1 " was " $x$ " and then " $n$ ", and a diamond with digit " 2 " was " $\mathrm{z}$ " and then " $\mathrm{m}$." The mappings 
TABLE 1 | Demographic characteristics of the open-skilled, closed-skilled and control participants.

\begin{tabular}{|c|c|c|c|c|}
\hline & Open-skilled & Closed-skilled & Control & $F, p$ \\
\hline Age, M (SD) & $21.1(2.2)$ & $21.1(2.0)$ & $21.8(2.1)$ & $F=0.77, p=0.466$ \\
\hline Weight kg, M (SD) & $67.2(11.6)$ & $58.3(9.4)$ & $57.1(10.2)$ & $F=5.00, p=0.010$ \\
\hline Height cm, M (SD) & $170.3(8.4)$ & $169.9(7.4)$ & $165.1(7.5)$ & $F=2.55, p=0.088$ \\
\hline BMl kg/m², M (SD) & $22.9(2.4)$ & $20.1(2.0)$ & $20.9(2.6)$ & $F=7.06, p=0.002$ \\
\hline $\begin{array}{l}\text { Years of professional motor skill } \\
\text { practices*, M (SD) }\end{array}$ & $11.3(2.7)$ & $7.9(1.6)$ & N.A. & $F=179.35, p<0.001$ \\
\hline $\begin{array}{l}\text { Hours of professional motor skill } \\
\text { practices each week, M (SD) }\end{array}$ & $8.3(1.8)$ & $8.6(1.6)$ & N.A. & $F=216.93 p<0.001$ \\
\hline VO2max mL* $\mathrm{kg}^{-1 *} \min ^{-1}, \mathrm{M}(\mathrm{SD})$ & $54.9(9.3)$ & $55.0(10.2)$ & $47.4(10.4)$ & $F=3.42, p=0.040$ \\
\hline Other expertise outside of sports & $\begin{array}{l}\text { Two participants engaged in } \\
\text { playing musical instrument }\end{array}$ & $\begin{array}{l}\text { Two participants engaged in } \\
\text { playing musical instrument; one } \\
\text { player in swimming }\end{array}$ & $\begin{array}{l}\text { Two participants engaged } \\
\text { in playing musical } \\
\text { instrument; one player in } \\
\text { wing chun }\end{array}$ & N.A. \\
\hline
\end{tabular}

* Denotes the regular motor skill practices under the coach guidance.

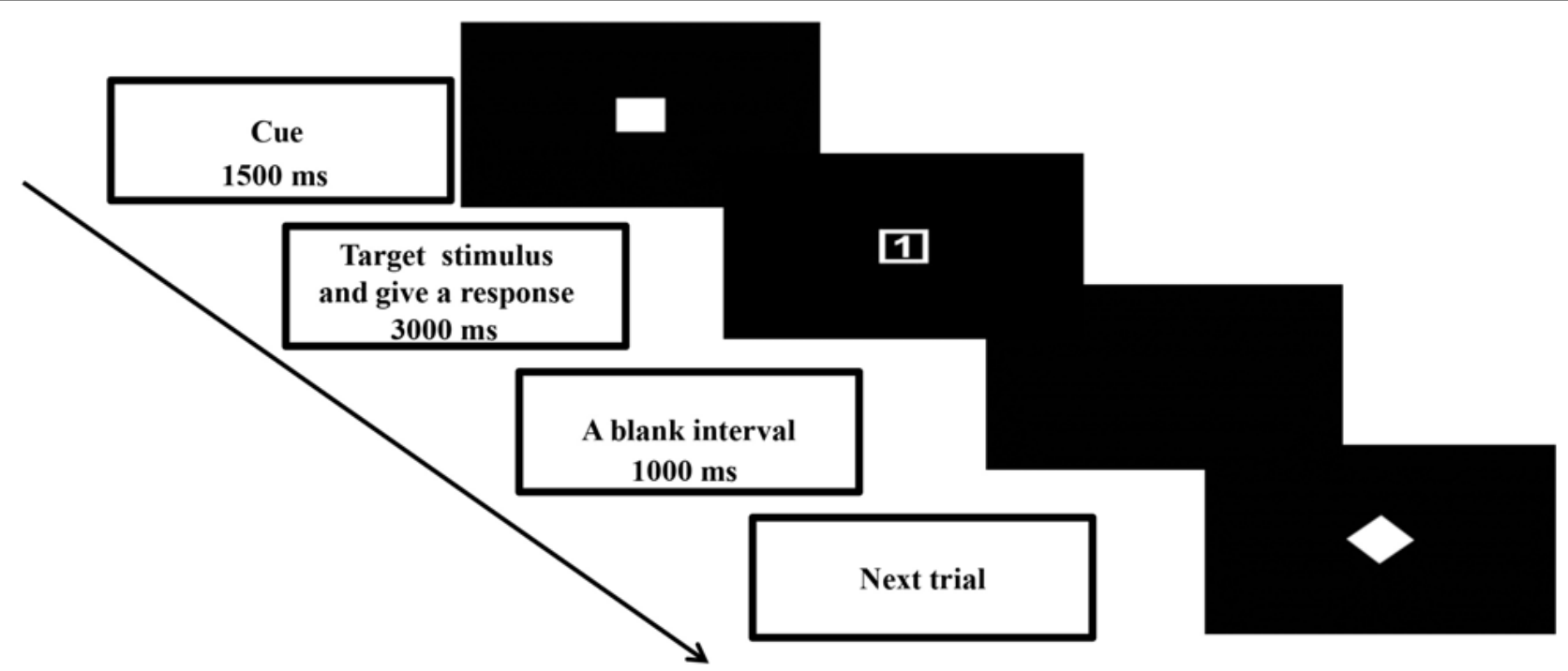

FIGURE 1 | Schematic illustration of one typical trial in the cued task-switching paradigm.

between cue stimulus (square or diamond) and two response selection rules were counterbalanced across participants. Only the $75 \%$ validity condition had congruent and incongruent trials. Congruent trials featured the same hollow square or diamond shapes appearing in the cue and target. Incongruent trials were when the shapes displayed in the cue and target differed. Only valid congruent trials in the $75 \%$ validity condition were included in the data analyses. Each trial was defined as "repeat" or "switch" depending on the response selection rule. A repeat trial was that the response selection rule was the same as that in the previous trial; whereas that of a switch trial was different from the previous trial.

The ratio of the three types of cue validities was 1:1:1. There was same ratio of repeat to switch trials in each block. Trials were organized in counterbalanced orders and grouped into nine blocks, and each block had 140 trials. It took around 9 min to complete one block followed by a 4 -to-5 min break. NeuroScan Stim2 software (NeuroScan, Inc., Sterling, VA, United States) was used for the fabrication of the trials. The time for completing the experimental task was approximately $1.5 \mathrm{~h}$.

\section{Data Collection Procedures Preparation}

Each participant was asked to complete the demographic information sheet, which included years for professional motor skill practices, hours for professional motor skill practices per week, sports categories, and other expertise outside of sports (Table 1). Before engaging in the experimental task, each participant sat on a comfortable chair in front of a table inside a dimly lit and electrically isolated sound-proof chamber. A 15inch computer monitor for showing trials was placed on the table at a distance of 65-75 cm. Each participant was required to first complete 100 practice trials. Standardized instructions and feedback were given to the participant throughout the training block. This was followed by a test block in which the 
participant completed 50 task trials and reached $90 \%$ accuracy before entering into the experiment. If the participant achieved an accuracy rate of less than $90 \%$, he or she repeated the training block. The participant was also reminded to minimize eye blinks and to keep his or her eyes at the center of the monitor throughout the task.

\section{Acquisition of ERP Data}

Participants' EEG signals were captured by a 64-channel Quik-cap equipped with $90 \mathrm{~mm} \mathrm{Ag} / \mathrm{AgCl}$ sintered electrodes, SynAmps2 Digital DC EEG amplifier, and Curry 7 software (NeuroScan, Inc., Sterling, VA, United States). Vertical and horizontal electrooculograms (EOGs) were captured with two pairs of electrodes placed on the supra- and infra-orbital areas of the left eye and the left and right orbital rims of both eyes, respectively. A ground electrode was positioned on the forehead in front of the $\mathrm{Cz}$ electrode. All the channels were referenced to the electrodes on the left and right mastoids. The EEG and EOG signals were sampled at a rate of $1000 \mathrm{~Hz} / \mathrm{channel}$. All EEG/EOG electrode impedances were set to below $5 \mathrm{k} \Omega$. EEG signals were recorded from the beginning of each block of experimental tasks. The timing of all stimuli was recorded by Curry 7 software.

Offline signal preprocessing also employed Curry 7 software. EEG signals were digitally filtered with a band pass from 0.01 to $30 \mathrm{~Hz}$. The covariance analysis algorithm was used when eye movement was detected. Then the EEG signals were segmented into the cue- and stimulus-locked epochs. Cuelocked epochs were defined as $-200 \mathrm{~ms}$ before the cue to $1,500 \mathrm{~ms}$ after the cue, and stimulus-locked epochs were defined as $-200 \mathrm{~ms}$ before the target to $1,000 \mathrm{~ms}$ after the target. Baseline corrections were referenced to the pre-stimulus interval. Epochs with an amplitude exceeding $\pm 80 \mu \mathrm{v}$ and trials with incorrect responses were excluded from the subsequent averaging procedure. The cue- and stimulus-locked waveforms of each electrode were averaged separately for three cue validities (100, 75 versus 50\%) and two task conditions (repeat versus switch). The number of epochs extracted for data analysis for each cue validity in each of the repeat or switch trials was around 140 for each group.

\section{Data Analysis}

As the behavioral data of this study shared the same data set of a previous study conducted by the same research team, the detailed methods of analyzing the behavioral results of the participants can be found in Yu et al. (2017) and will not be repeated here. Analyses of the ERP data included the cue-locked P3, CNV, N2 and the stimulus-locked P3 elicited when participants engaged in the behavioral task. Independent component analysis (ICA) was conducted to confirm the timewindows set for extracting signals related to the cue-locked P3 (350-550 ms post-cue), CNV (1200-1500 ms post-cue), N2 (200-300 ms post-target), and stimulus-locked P3 (300-600 ms post-target). A short time-window was set for the cue-locked P3 for lowering the possible interferences to the CNV, as ICA results showed a slight overlap in the time-windows of these two components. In the analysis, the electrodes at the midline sites $(\mathrm{Fz}, \mathrm{Cz}$, and $\mathrm{Pz})$ were included making reference to the results of previous studies that switch effects were maximal at the midline electrode sites (Gajewski and Falkenstein, 2011; Hsieh and $\mathrm{Wu}, 2011$; Li et al., 2012). A four-way repeated measures ANCOVA for validity $(100,75$ versus $50 \%) \times$ trial (repeat versus switch $) \times$ site $(\mathrm{Fz}, \mathrm{Cz}$ versus $\mathrm{Pz}) \times$ group (open-skilled, closed-skilled versus control) was conducted to test the mean amplitudes of the cue-locked P3, CNV, N2, and stimulus-locked P3. The years of participants' professional motor skill practices was the only covariate entered because of the significant between-group differences in this variable (Table 1). Another reason was that the years of professional motor skill practices rather than the MBI and VO2max was revealed to significantly predict the participants' performances on the behavioral tasks in Yu et al. (2017). Post hoc pairwise comparisons with the Bonferroni adjustment were applied when significant main or interaction effects were observed. This study only included the amplitudes rather than latencies in the ERP data analyses because previous study reported no significant differences between groups and between trials on the P3 latency (Scisco et al., 2008). As the switch cost of response time was related to amplitudes of cue- or stimulus-locked P3 components (Jamadar et al., 2010; Li et al., 2012), the present study examined the relations among cue- and stimulus-locked P3 and behavioral performance (i.e., switch cost of response time) for different motor skills by using a hierarchical, stepwise regression analysis for each of the validity conditions. For each regression equation, two regressors were the mean amplitude differences between switch and repeat trials of cue- $\left(\mathrm{cP}_{\mathrm{S}}-\mathrm{cP} 3_{R}\right)$ and stimulus-locked $\mathrm{P} 3\left(\mathrm{sP} 3_{\mathrm{S}}-\mathrm{sP} 3_{R}\right)$; two other regressors were the identities of the open- and closed-skilled groups (with the control group as the reference). The two-way interaction terms for the neural processes and group identities were $\mathrm{cP} 3_{\mathrm{S}}-\mathrm{cP} 3_{\mathrm{R}} \times$ openskilled; $\mathrm{CP}_{3}-\mathrm{cP} 3_{\mathrm{R}} \times$ closed-skilled; $\mathrm{sP} 3_{\mathrm{S}}-\mathrm{sP} 3_{\mathrm{R}} \times$ open-skilled; and $\mathrm{sP} 3 \mathrm{~s}-\mathrm{sP} 3_{\mathrm{R}} \times$ closed-skilled. The variance inflation factor (VIF) $\geq 10$ and Pearson's correlation $\geq 0.85$ were considered as indicators of strong multicollinearity between any of the two independent variables in a hierarchical regression model. The results showed no variable displayed strong multicollinearity, suggesting that none of the variables were related to each other. All analyses were performed with IBM SPSS statistics version 20.0 (IBM, Chicago, IL, United States).

\section{RESULTS}

The main behavioral variable was the switch cost of response time, which was defined as the difference in the reaction times between the switch and repeat trials. Two-way repeated measure ANOVA of validity (100, 75 versus $50 \%) \times$ group (open-skilled, closed-skilled versus control) testing the effects on the switch cost of response times indicated that the validity $\times$ group effect on the switch cost of response times was marginally significant $(p=0.053)$. Participants in the open-skilled group showed significantly fewer switch cost values than the closedskilled $(p=0.023)$ and control $(p<0.001)$ groups in the $100 \%$ validity condition (Figure 2). Participants in both the open- $(p<0.001)$ and closed-skilled $(p=0.033)$ groups showed 


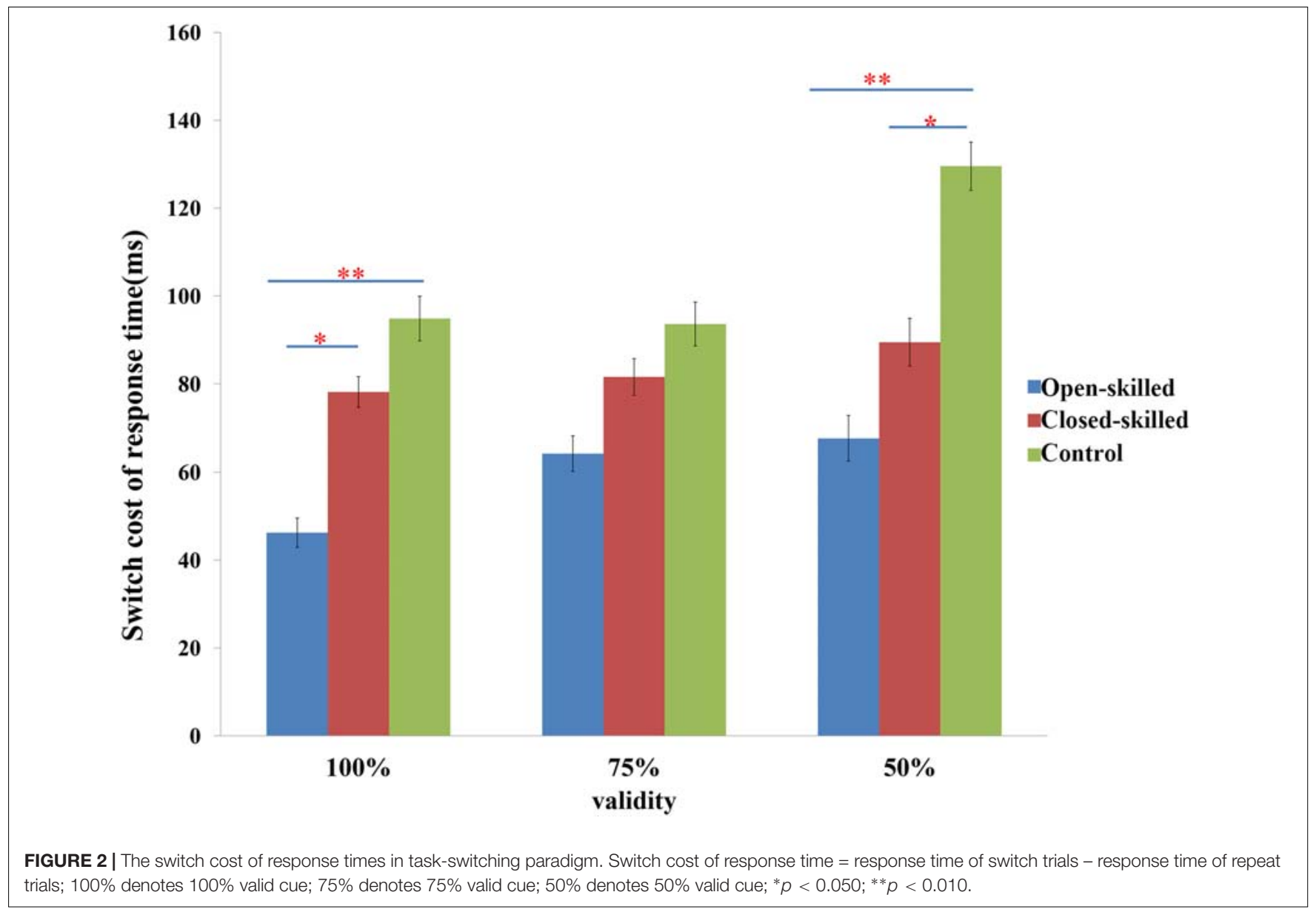

significantly fewer switch cost values than the control group in the $50 \%$ validity condition (Figure 2 ). No significant differences in switch costs were revealed between the open- and closed-skilled groups $(p=0.473)$ (Figure 2$)$. Their details can be found in Yu et al. (2017).

\section{Cue-Locked P3 (350-550 ms)}

Figure 3 presents topographic maps (3A) and waveforms (3B) of the cue-locked P3 for the open-skilled, closed-skilled, and control groups. The covariate of years of professional motor skill practices $\left[F(1,50)=0.54, p=0.466, \eta_{\mathrm{p}}^{2}=0.011\right]$ was not significant. The validity $\times$ trial $\times$ site $\times$ group effect $\left[F(6.264,156.602)=2.66, p=0.016, \eta_{p}^{2}=0.096\right]$ was found significant. The site main effect was also significant $\left[F(1.488,74.389)=9.61, p=0.001, \eta_{\mathrm{p}}^{2}=0.161\right]$. However, the validity $\left[F(2,100)=0.13, p=0.880, \eta_{\mathrm{p}}^{2}=0.003\right]$, trial $\left[F(1,50)=0.002, p=0.968, \eta_{\mathrm{p}}^{2}<0.001\right]$, and group effects $\left[F(2,50)=0.42, p=0.657, \eta_{\mathrm{p}}^{2}=0.017\right]$ on the amplitudes of cue-locked $\mathrm{P} 3$ were not significant.

Post hoc analyses on trial $\times$ site $\times$ group effect were conducted separately at each level of validity. The trial $\times$ site $\times$ group effect was only significant in the $100 \%$ validity condition $\left[F(3.351,85.442)=5.46, p=0.001, \eta_{\mathrm{p}}^{2}=0.177\right]$ but not in the $75 \%\left[F(2.752,70.179)=1.11, p=0.348, \eta_{\mathrm{p}}^{2}=0.042\right]$ and $50 \%$ validity conditions $\left[F(3.249,82.856)=0.13, p=0.952, \eta_{\mathrm{p}}^{2}=0.005\right]$. Hence, the trial $\times$ group effect for the $100 \%$ validity condition was further examined at each of the electrode sites. The trial $\times$ group effect was significant at $\mathrm{Fz}\left[F(2,51)=6.82, p=0.002, \eta_{\mathrm{p}}^{2}=0.211\right]$ and $\mathrm{Pz}\left[F(2,51)=8.03, p=0.001, \eta_{\mathrm{p}}^{2}=0.239\right]$ but not at $\mathrm{Cz}$ $\left[F(2,51)=1.32, p=0.28, \eta_{p}^{2}=0.049\right]$. At Fz, the open-skilled group showed marginally less positive-going cue-locked P3 in the switch than repeat trials $(p=0.056)$ in the $100 \%$ validity condition, whereas the closed-skilled group showed an opposite trend whereby the cue-locked P3 was significantly more positivegoing in the switch than repeat trials $(p=0.003)$. The control group did not show significant between-trial-type differences in the amplitudes of cue-locked P3 at Fz $(p=0.822)$ (Figure 3C). At $\mathrm{Pz}$, the open-skilled group showed a less positive-going cuelocked P3 in the switch than repeat trials $(p=0.011)$. The closed-skilled group, however, did not show significant betweentrial-type differences in the amplitudes of cue-locked P3 at $\mathrm{Pz}(p=0.523)$. The control group showed significantly more positive-going cue-locked $\mathrm{P} 3$ at $\mathrm{Pz}$ in the switch than repeat trials $(p=0.004)$.

\section{CNV (1200-1500 ms)}

In $\mathrm{CNV}$, the covariate of years of professional motor skill practices was found significant $[F(1,50)=4.21, p=0.045$, 
A

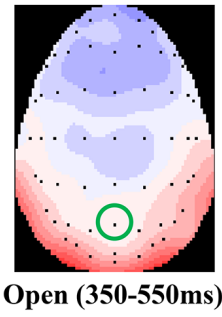

B
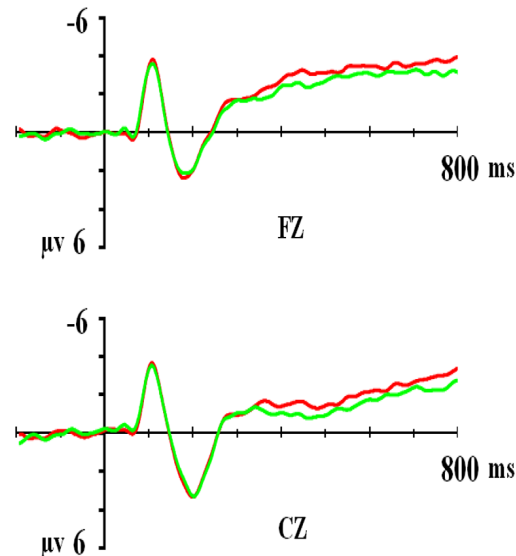

$\mu v 6$

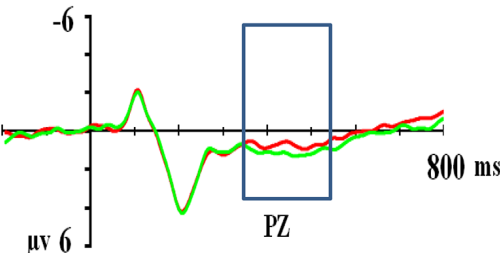

Open

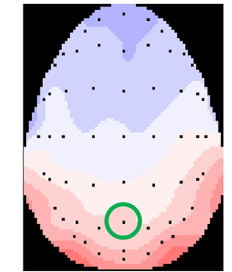

Closed (350-550ms)

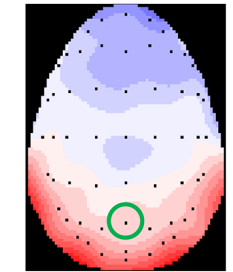

Control (350-550ms)
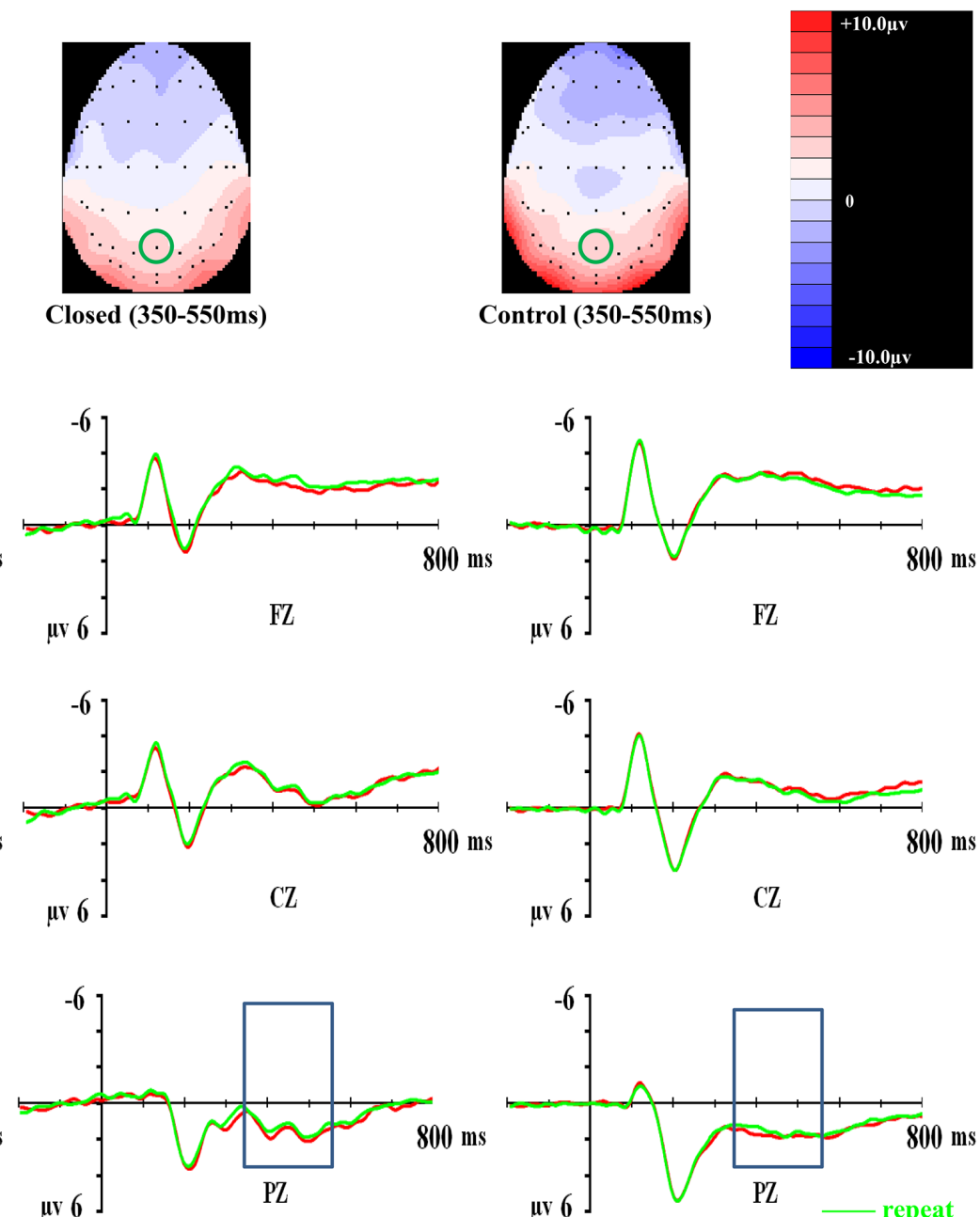

Closed

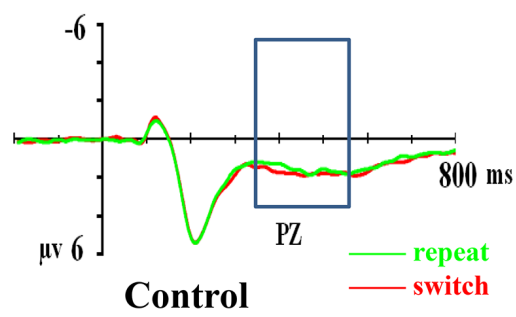

C

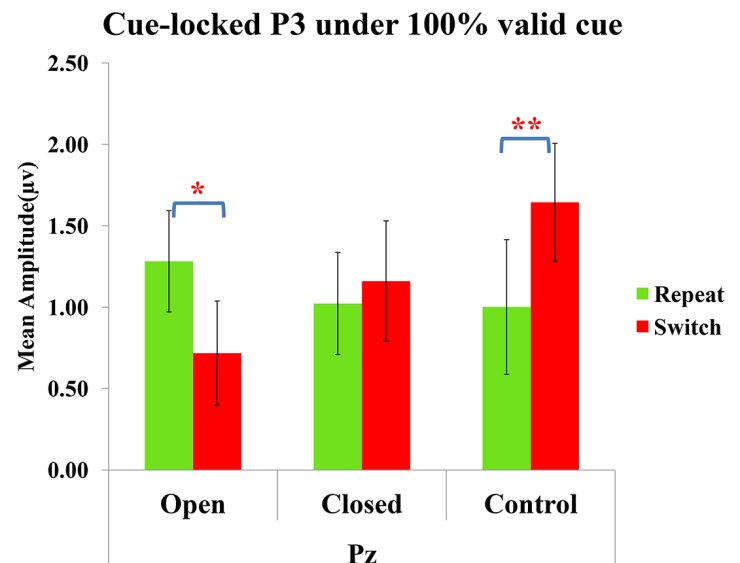

\section{Cue-locked P3 under 50\% valid cue}

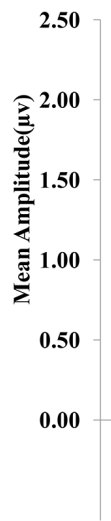

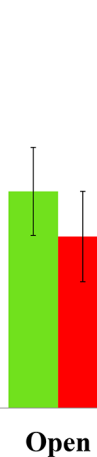
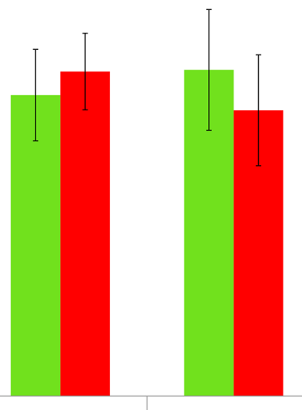

Repeat

- Switch

FIGURE 3 | Analyses of the cue-locked P3 among three groups of participants. (A) Topographical distributions within the 350-550 ms post-cue time-window regardless of trial types and validities; the Pz site is indicated with the green circle. (B) Mean amplitudes of the waveforms of the repeat (in green) and switch (in red) trial-types regardless of validities; the 350-550 ms time-window at Pz is indicated with the rectangular boxes. (C) Comparisons of the mean amplitudes between the repeat and switch trial-types at the Pz site for the 100\% (left panel) and 50\% (right panel) validity conditions. Error bars indicate SEM; ${ }^{*} p<0.050 ;{ }^{* *} p<0.010$. 
$\left.\eta_{\mathrm{p}}^{2}=0.078\right]$. The validity $\times$ trial $\times$ site $\times$ group effect $\left[F(6.118,152.946)=0.55, p=0.772, \eta_{\mathrm{p}}^{2}=0.022\right]$ on the amplitudes of $\mathrm{CNV}$ was not significant (Figure 4). The validity effect $\left[F(2,100)=7.20, p=0.001, \eta_{\mathrm{p}}^{2}=0.126\right]$ was significant. However, trial $\left[F(1,50)=0.06, p=0.811, \eta_{\mathrm{p}}^{2}=0.001\right]$, site $[F(2,100)=1.54$, $\left.p=0.221, \eta_{\mathrm{p}}^{2}=0.030\right]$, and group effects $[F(2,50)=1.06, p=0.354$, $\left.\eta_{\mathrm{p}}^{2}=0.041\right]$ were not significant. Post hoc analysis showed that $\mathrm{CNV}$ in the $100 \%$ validity condition was more negativegoing than those in $75 \%(p<0.001)$ and 50\% $(p<0.001)$ validity conditions.

\section{N2 (200-300 ms)}

The covariate of years of professional motor skill practices was found not statistically significant $[F(1,50)=0.29, p=0.596$, $\left.\eta_{\mathrm{p}}^{2}=0.006\right]$. The validity $[F(1.656,82.825)=1.85, p=0.170$, $\left.\eta_{\mathrm{p}}^{2}=0.036\right]$, trial $\left[F(1,50)=1.63, p=0.208, \eta_{\mathrm{p}}^{2}=0.031\right]$, group $\left[F(2,50)=0.42, p=0.658, \eta_{p}^{2}=0.017\right]$, and the validity $\times$ trial $\times$ site $\times$ group effects $[F(5.866,146.655)=1.23$, $\left.p=0.295, \eta_{\mathrm{p}}^{2}=0.047\right]$ on the amplitudes of $\mathrm{N} 2$ were also not significant. However, the site $[F(1.275,63.730)=5.86, p=0.012$, $\left.\eta_{\mathrm{p}}^{2}=0.105\right]$, and validity $\times$ trial $\times$ site $\times$ covariate $($ years of professional motor skill practices) effect were significant $\left[F(2.933,146.655)=2.80, p=0.043, \eta_{\mathrm{p}}^{2}=0.053\right]$. Post hoc analysis showed that $\mathrm{N} 2$ in $100 \%$ validity conditions was more negativegoing in the switch than repeat trials at $\mathrm{Fz}(p=0.034), \mathrm{Cz}$ $(p<0.01)$, and $\mathrm{Pz}(p<0.01)$, but this effect was not found in 75 and $50 \%$ validity conditions. In both 75 and $50 \%$ validity conditions, N2 was more negative-going at $\mathrm{Fz}(p s<0.05)$ than $\mathrm{Cz}$ and $\mathrm{Pz}$. Figure 5A presents the topographic maps of the $\mathrm{N} 2$ component.

\section{Stimulus-Locked P3 (300-600 ms)}

The topographic maps (5A) and waveforms (5B) of the stimuluslocked P3 for the open-skilled, closed-skilled, and control groups are presented in Figure 5. The covariate of years of professional motor skill practices was significant $[F(1,50)=4.46$, $\left.p=0.040, \eta_{\mathrm{p}}^{2}=0.082\right]$. The validity $\times$ trial $\times$ site $\times$ group effect $\left[F(5.671,141.771)=2.25, p=0.045, \eta_{\mathrm{p}}^{2}=0.082\right]$ on the amplitudes of stimulus-locked $\mathrm{P} 3$ was found significant. The site $\left[F(1.474,73.719)=4.14, p=0.031, \eta_{\mathrm{p}}^{2}=0.076\right]$ and group effects $\left[F(2,50)=5.27, p=0.008, \eta_{\mathrm{p}}^{2}=0.174\right]$ were significant. The trial effect was marginally significant $[F(1,50)=3.93, p=0.053$, $\left.\eta_{\mathrm{p}}^{2}=0.073\right]$. However, the validity $[F(2,100)=0.33, p=0.719$, $\left.\eta_{\mathrm{p}}^{2}=0.007\right]$ effect was not significant.

By adjusting years of professional motor skill practices, post hoc analysis showed significant trial $\times$ site $\times$ group effect only in the $50 \%$ validity condition $[F(3.267,81.670)=3.48$, $\left.p=0.017, \eta_{\mathrm{p}}^{2}=0.122\right]$ (Figure 5C), but not in the $100 \%$ $\left[F(2.824,70.610)=1.81, p=0.322, \eta_{\mathrm{p}}^{2}=0.045\right]$ and $75 \%$ validity conditions $\left[F(2.897,72.437)=1.37, p=0.260, \eta_{\mathrm{p}}^{2}=0.052\right]$. Interestingly, the results were different from those found in cuelocked P3, in which the same three-way interaction effect was significant in the $100 \%$ validity condition. The trial $\times$ group effect in the $50 \%$ validity condition was further tested separately for $\mathrm{Fz}, \mathrm{Cz}$, and Pz. The trial $\times$ group effect was found significant at the $\mathrm{Cz}$ and $\mathrm{Pz}\left[F(2,51)=3.52, p=0.037, \eta_{\mathrm{p}}^{2}=0.121\right.$; $F(2,51)=4.14, p=0.021, \eta_{\mathrm{p}}^{2}=0.140$, respectively], but not at the Fz $\left[F(2,51)=2.02, p=0.143, \eta_{\mathrm{p}}^{2}=0.073\right]$. At Pz, both the open-skilled $(p=0.008)$ and closed-skilled $(p=0.002)$ groups showed significantly less positive-going stimulus-locked P3 in the switch than repeat trials (Figure 5C). The control group, however, showed no significant between-trial-type difference in the stimulus-locked P3 amplitudes at $\mathrm{Pz}(p=0.630)$. At $\mathrm{Cz}$, the open-skilled $(p<0.001)$ and closed-skilled $(p=0.038)$ groups had significantly less positive-going stimulus-locked P3 in the switch than repeat trials; whereas the control group did not show any significant between-trial-type differences in the amplitudes of stimulus-locked P3 $(p=0.838)$.

\section{Hierarchical Stepwise Regression}

In the $100 \%$ validity condition, the regression model was significant, $R^{2}=0.226, F(4,49)=3.579, p=0.012$, with the only significant regressor in the model being the open-skilled group as a group identity $(\beta=-0.573, p=0.001)$ (Table 2). Other regressors (e.g., $\mathrm{cP} 3_{\mathrm{S}}-\mathrm{cP} 3_{\mathrm{R}}$ and $\mathrm{sP} 3_{\mathrm{s}}-\mathrm{sP} 3_{\mathrm{R}}$, closed-skilled group) were not significant $(|\beta|<0.285$, $p s>0.057)$. The changes in the variance explained by the open-skilled group regressor were also significant $\left[\Delta R^{2}=0.182, F(4,45)=3.455\right.$, $p=0.015]$. The effect of $\mathrm{cP} 3_{\mathrm{S}}-\mathrm{cP} 3_{\mathrm{R}} \times$ open-skilled was significant $(\beta=0.475, p=0.007)$, whereas $c \mathrm{PP} 3_{-}-\mathrm{cP} 3_{\mathrm{R}}(\beta=-0.431$, $p=0.072)$ and $\mathrm{cP}_{\mathrm{S}} \mathrm{s}-\mathrm{CP} 3_{\mathrm{R}} \times$ closed-skilled $(\beta=0.247$, $p=0.205$ ) did not show significant impacts (Figure 6A). These results suggested that the $\mathrm{cP}_{\mathrm{S}}-\mathrm{cP} 3_{\mathrm{R}}$, which was associated with proactive control for task switching, showed significant correlation with the switch cost of response times among the open-skilled participants but not among the closed-skilled and control participants.

In the $50 \%$ validity condition, the regression model was significant, $R^{2}=0.211, F(4,49)=2.782, p=0.037$, for both the open- and closed-skilled groups as group identities were identified as significant regressors $(\beta=-0.474, p=0.003$; $\beta=-0.397, p=0.012$, respectively) (Figure 6B). The other two regressors, $c \mathrm{P} 33_{\mathrm{S}}-\mathrm{cP} 3_{\mathrm{R}}$ and $\mathrm{sP} 3_{\mathrm{S}}-\mathrm{sP} 3_{\mathrm{R}}$, were not significant ( $\beta=-0.008, p=0.949 ; \beta=-0.062, p=0.643$, respectively). The changes in the variance are explained by the significance of the open- and closed-skilled groups' regressors $\left[\Delta R^{2}=0.157\right.$, $F(4,45)=3.057, p=0.043]$. The effects ofsP $3_{\mathrm{S}}-\mathrm{sP} 3_{\mathrm{R}}(\beta=-0.550$, $p=0.020)$, open-skilled $(\beta=-0.363, p=0.031)$, closed-skilled $(\beta=-0.347, p=0.023), \mathrm{sP}_{\mathrm{s}} \mathrm{sP} 3_{\mathrm{R}} \times$ open-skilled $(\beta=0.464$, $p=0.022)$, andsP $3_{\mathrm{S}}-\mathrm{sP} 3_{\mathrm{R}} \times$ closed-skilled $(\beta=0.519, p=0.012)$ were the significant predictors, suggesting that the correlations between $\mathrm{sP} 3_{\mathrm{S}}-\mathrm{sP} 3_{\mathrm{R}}$ and the switch cost of response time in the open- and closed-skilled groups were significantly different from those of the control group. A follow-up analysis suggested that such correlation was significantly negative in the control participants $(r=-0.534, p=0.022)$, but not significant in the open-skilled $(r=0.262, p=0.294)$ and closed-skilled $(r=0.274$, $p=0.270$ ) participants (Figure 6B).

In the $75 \%$ validity condition, the regression model was also significant, $R^{2}=0.255, F(4,49)=4.203, p=0.005$, with $\mathrm{cP}_{3} \mathrm{~s}-\mathrm{cP} 3_{\mathrm{R}}$ $(\beta=0.320, p=0.023)$ and $\mathrm{sP} 3 \mathrm{~s}-\mathrm{sP} 3_{\mathrm{R}}(\beta=-0.378, p=0.004)$ 


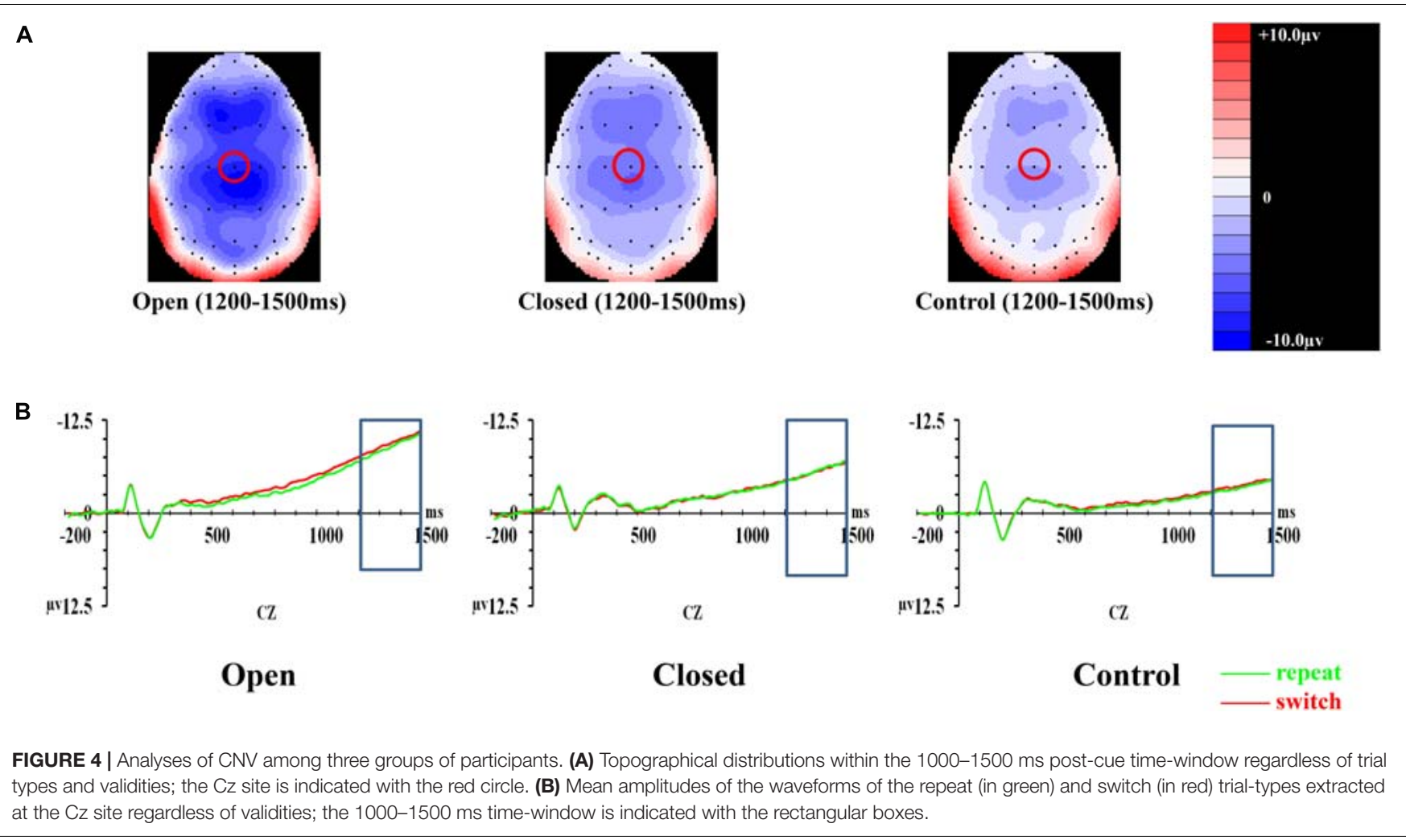

being significant regressors in the model. No other significant regressors were found $\left[R^{2}=0.277, F(8,45)=2.151, p=0.050\right]$ (Figure 6C). Both $\mathrm{cP} 3 \mathrm{~s}-\mathrm{cP} 3 \mathrm{r}(r=0.317, p=0.020)$ and sSP3ssP3r $(r=-0.333, p=0.014)$ showed significant correlations with the participants' switch cost of response times, regardless of the subgroups.

\section{DISCUSSION}

The current study investigated how motor skill experiences modulated proactive and reactive controls of executive function in healthy adults. New findings are that the open-skilled participants, when compared with the other two groups, showed significantly less positive-going parietal cue-locked P3 in switch than repeat trials, which coupled with better performances on task-switching in the predictive condition. These suggest that proactive control was unique to the open-skilled participants. It appears that they might have been able to deploy fewer attentional resources in proactively updating the new action rule than the closed-skilled participants. These findings corroborate with the results of the regression analysis, which show that better proactive control for task switching was associated with the between-trial difference in the cue-locked P3 amplitudes for the open- but not closed-skilled participants. On the contrary, in the non-predictive condition both the open- and closed-skilled participants showed significantly less positivegoing parietal stimulus-locked P3 in the switch than repeat trials, which could not be found in the control participants.
These results indicate that, prior experiences in motor skill training, regardless of the types of motor skills developed, would result in fewer deployments of attentional resources for reactively updating the new action rule under non-anticipatory circumstances. Our findings further confirm the dissociation of proactive and reactive controls in relation to their modulations by different motor-skill experiences. In particular, both proactive and reactive controls of executive functions could be enhanced by intensively exposing individuals to anticipatory and nonanticipatory enriched environments.

The results of the $75 \%$ validity condition will not be discussed because no significant findings were revealed in the comparisons of the ERP data.

\section{Proactive Control and Open-Skill Experience}

The experimental task used in the present study required the participants to switch between two sets of action rules. Our ERP results show less positive cue-locked P3 in switch than repeat trials observed among the open-skilled participants, which was not the case in the closed-skilled and control groups. These findings indicate that open-skilled participants deployed fewer attentional resources when proactively updating the new action rule than their closed-skilled counterparts. In addition, behavioral results on the same groups of participants reported by in Yu et al. (2017) showed that open-skilled participants exhibited smaller switch cost of response times in the predictive condition (100\% validity) than closed-skilled participants. The ERP findings of the cue-locked P3 and the published behavioral 


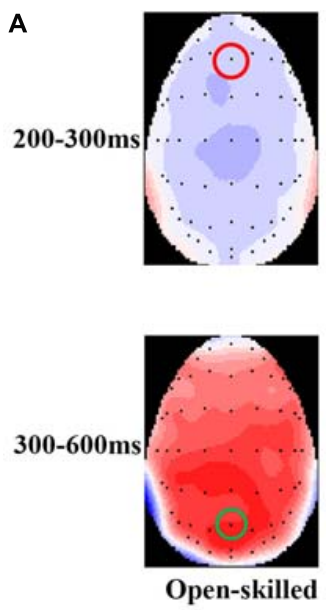

B
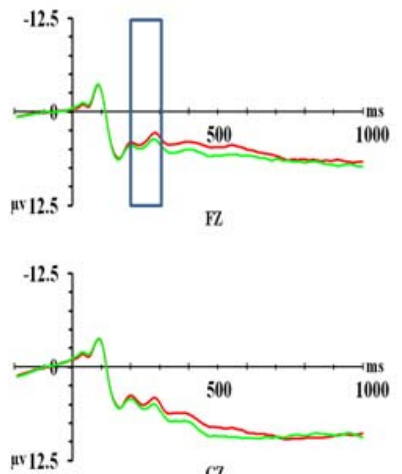

CZ

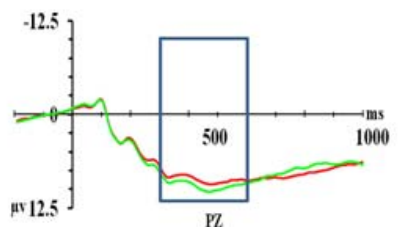

Open-skilled
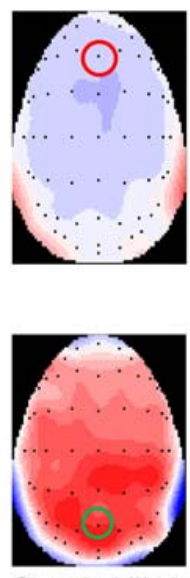

Closed-skilled
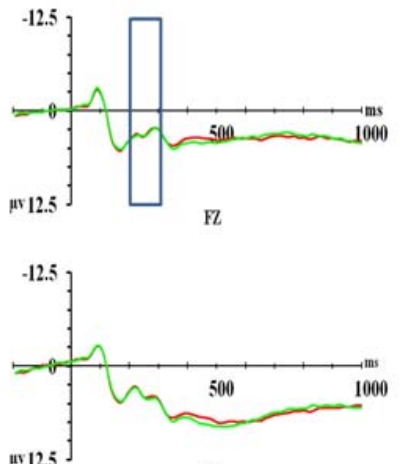

CZ

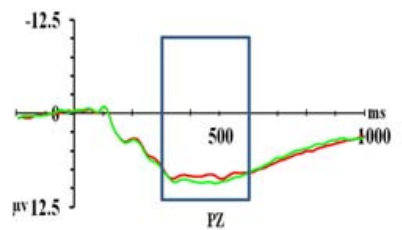

Closed-skilled
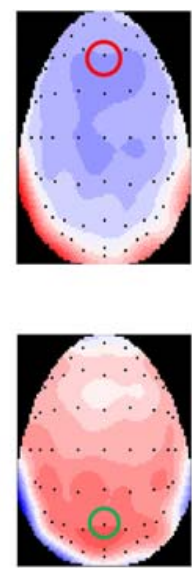

Control
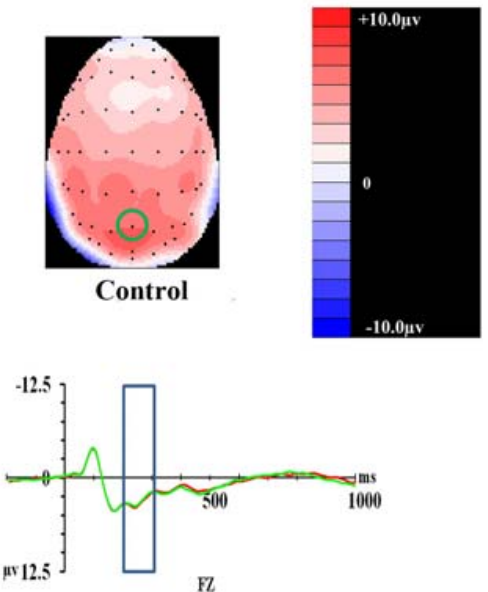

FZ

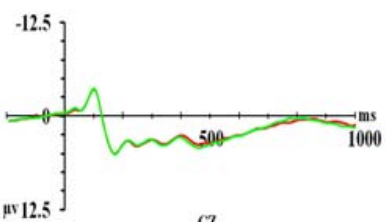

CZ

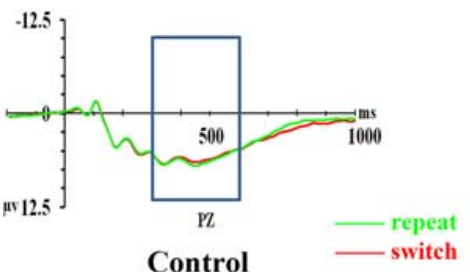

Stimulus-locked P300 under $50 \%$ valid cue

C Stimulus-locked P300 under $100 \%$ valid cue
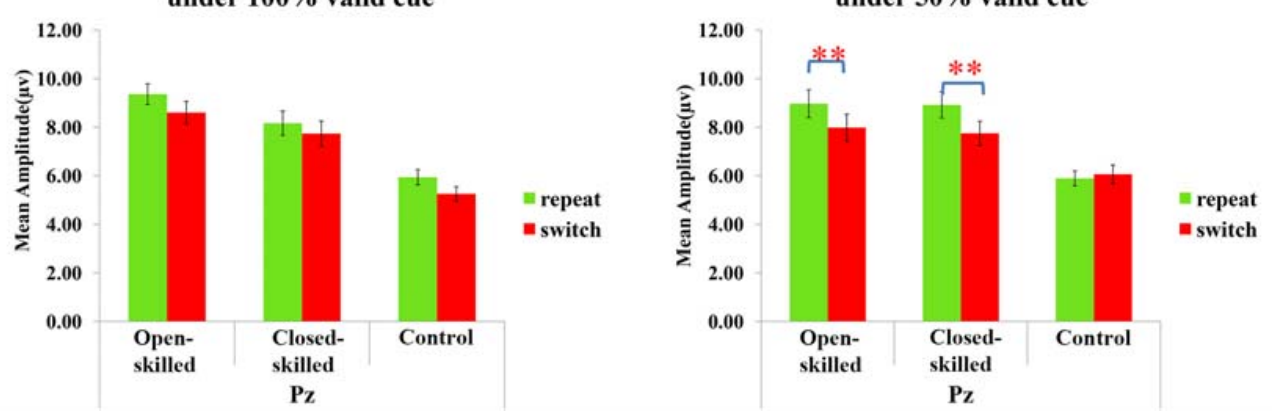

FIGURE 5 | Analyses of the N2 and stimulus-locked P3 among three groups of participants. (A) Topographical distributions of N2 (200-300 ms) and stimulus-locked P3 (300-600 ms) post-target time-window regardless of trial types and validities; the Fz site is indicated with the red circle, and the Pz site is indicated with the green circle. (B) Mean amplitudes of the waveforms of the repeat (in green) and switch (in red) trial-types regardless of validities; the 200-300 ms time-window at Fz and 300-600 ms time-window at Pz are indicated with the rectangular boxes. (C) Comparisons of the mean amplitudes between the repeat and switch trial-types at the Pz site for the $100 \%$ (left panel) and $50 \%$ (right panel) validity conditions. ${ }^{* *} p<0.010$. 
TABLE 2 | Results of hierarchical stepwise regression of amplitudes of the cue- and stimulus-locked P3 for predicting the switch cost of response times in the 100, 50, and $75 \%$ cue validity conditions.

\begin{tabular}{|c|c|c|c|}
\hline & $100 \%$ cue validity & $50 \%$ cue validity & $75 \%$ cue validity \\
\hline & Step 1 & Step 1 & Step 1 \\
\hline & $\begin{array}{c}\text { Standardized regression } \\
\text { coefficients }(\boldsymbol{\beta})\end{array}$ & $\begin{array}{c}\text { Standardized regression } \\
\text { coefficients }(\beta)\end{array}$ & $\begin{array}{c}\text { Standardized regression } \\
\text { coefficients }(\beta)\end{array}$ \\
\hline$c P 3_{S}-c P 3_{R}$ & -0.075 & -0.008 & $0.320^{*}$ \\
\hline$s P 3_{S}-s P 3_{R}$ & 0.029 & -0.062 & $-0.378^{* *}$ \\
\hline Open-skilled group & $-0.573^{* *}$ & $-0.474^{*}$ & -0.139 \\
\hline Closed-skilled group & -0.284 & $-0.397^{* *}$ & -0.051 \\
\hline$R^{2}$ & 0.226 & 0.185 & 0.255 \\
\hline Adjusted $\mathrm{R}^{2}$ & 0.163 & 0.119 & 0.195 \\
\hline \multirow[t]{3}{*}{$F$} & $3.579 *$ & $2.782^{*}$ & $4.203^{* *}$ \\
\hline & Step2 & Step2 & Step2 \\
\hline & $\begin{array}{c}\text { Standardized regression } \\
\text { coefficients }(\beta)\end{array}$ & $\begin{array}{c}\text { Standardized regression } \\
\text { coefficients }(\beta)\end{array}$ & $\begin{array}{c}\text { Standardized regression } \\
\text { coefficients }(\beta)\end{array}$ \\
\hline$c P 3 s-c P 3 R$ & -0.431 & 0.010 & 0.445 \\
\hline$s P 3_{s}-s P 3_{R}$ & -0.262 & $-0.550^{*}$ & -0.138 \\
\hline Open-skilled group & $-0.393^{*}$ & $-0.363^{*}$ & -0.133 \\
\hline Closed-skilled group & -0.265 & $-0.347^{*}$ & -0.057 \\
\hline$c P 3 s-c P 3 R \times$ Open-skilled & $0.475^{* *}$ & 0.066 & -0.070 \\
\hline $\mathrm{CP} \mathrm{S}_{\mathrm{S}} \mathrm{cP} 3_{\mathrm{R}} \times$ Closed-skilled & 0.247 & 0.131 & -0.099 \\
\hline$s P 3_{S}-s P 3_{R} \times$ open-skilled & 0.293 & $0.464 *$ & -0.096 \\
\hline $\mathrm{sP}_{3}-\mathrm{sP} 3_{\mathrm{R}} \times$ closed-skilled & 0.225 & $0.519 *$ & -0.255 \\
\hline$R^{2}$ & 0.408 & 0.342 & 0.277 \\
\hline Adjusted $R^{2}$ & 0.303 & 0.225 & 0.148 \\
\hline$F$ & $3.876^{* *}$ & $2.925^{* *}$ & 2.151 \\
\hline$\Delta \mathrm{R}^{2}$ & 0.182 & 0.157 & 0.021 \\
\hline$\Delta F$ & $3.455^{*}$ & $2.685^{*}$ & 0.329 \\
\hline
\end{tabular}

${ }^{*} p<0.050 ;{ }^{*} p<0.010 ; R T$ denotes response time; $c P 3 \mathrm{~S}-c P 3 \mathrm{R}$ denotes difference of mean amplitudes between switch and repeat trial-types of cue-locked P3;

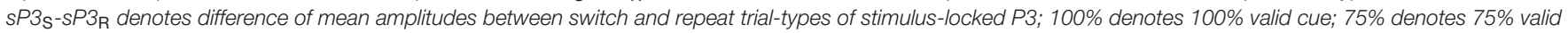
cue; $50 \%$ denotes $50 \%$ valid cue.

data suggest higher efficiency in updating the new action rule in proactive control than the closed-skilled participants. Our results are consistent with those reported in previous studies, which found participants engaged in open-skilled physical activities have higher efficiency in the updating process related to motor preparation. Open-skilled participants were proposed to have better motor-reprograming processes in terms of smaller timing errors than closed-skilled participants (Nakamoto and Mori, 2012). Jin et al. (2011) also found that professional badminton players had more accurate judgments of the placement of badminton strokes and larger P3a amplitude in the proactive anticipation than non-professional players, suggesting good anticipation ability. Mcrobert et al. (2011) also reported the openskilled participants had the higher online updating ability, with which they were more adaptive to dynamic environments in the anticipation. Bertollo et al. (2016) further explained that the higher efficiency in switching between the automatic and controlled processes among sport experts than amateurs is a reason for the former to proficiently adapt to the changing environment in open sports. When compared with amateur athletes, the high efficiency found among the open-skilled athletes was revealed to result in the employment of less cognitive resources in controlled processes (Babiloni et al., 2010).

In the present study, the open-skilled participants are badminton athletes whose experience is in updating opponent's changed kinematics information and overcoming interferences from previous deceptive movement patterns (Müller and Abernethy, 2012). They succeeded in winning the game mostly depending on how well they update environmental changes and anticipate their opponent's actions (Bianco et al., 2017b). With such a background, the open-skilled participants tend to deploy fewer attentional resources when updating the new action rules in proactive control for the switch trials, which was not the case in the closed-skilled and control participants. The significant positive correlations between the amplitudes of cue-locked P3 and the switch cost of response time in our results were revealed only in the participants of the open-skilled group, which further substantiate the uniqueness of proactive control to the openskilled participants.

No differences were revealed in the between-trial and between-group comparisons for the CNV. The non-significant between-group difference, supported by those reported in other 

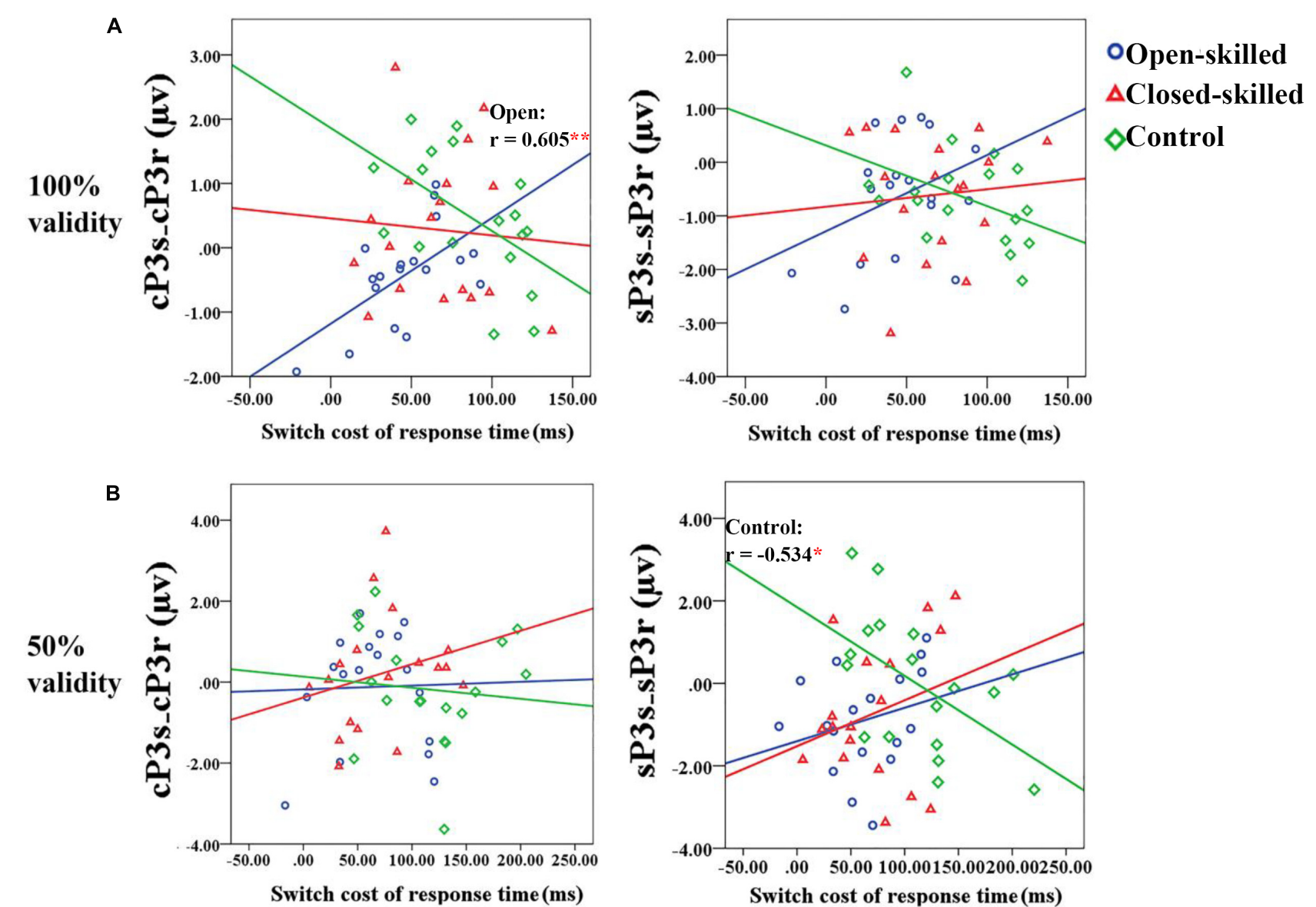

Switch cost of response time (ms)
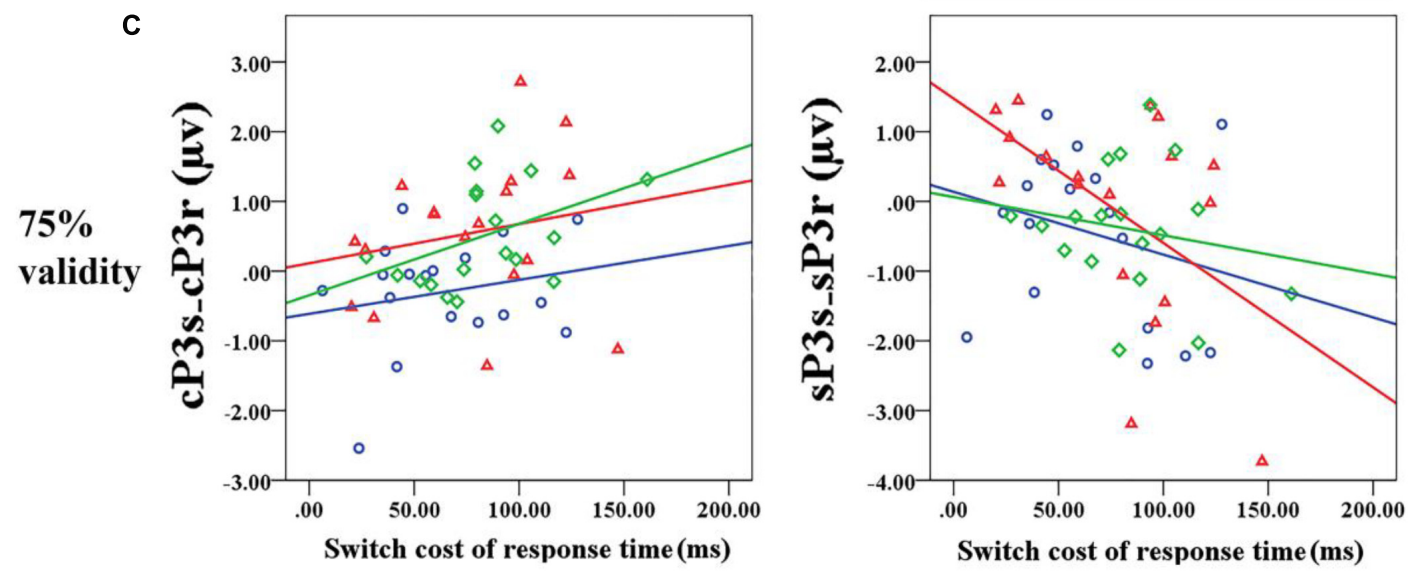

FIGURE 6 | Scatter plots showing the relationships between the differences of the mean amplitudes of the cue-locked P3 between switch and repeat trial-types $\left(\mathrm{CP} 3_{S}-\mathrm{cP} 3_{R}\right)$ (right panel) or that of the stimulus-locked P3 (sP3 $-\mathrm{sP} 3_{R}$ ) (right panel) and the switch cost of response time for the 100, 50 , and $75 \%$ validity conditions (from a to c) among the three groups of participants. (A) In the $100 \%$ validity condition, one significant correlation coefficient $(r=0.605, p=0.008)$ is revealed in the open-skilled group for the cue-locked P3 (cP3s-cP3r); the blue regression line presents the significant positive correlation between the two variables. (B) In the 50\% validity condition, one significant correlation coefficient ( $r=-0.534, p=0.022$ ) is revealed in the control group for the stimulus-locked P3 (sP3s-sP3r); the green regression line presents the significant negative correlation between the two variables. Only control group shows significant correlation. (C) In the $75 \%$ validity condition, no significant correlations are revealed. ${ }^{*} p<0.050 ;{ }^{*} p<0.010$.

study (Bianco et al., 2017b), suggests that the level of the top-down attentional control preparing for task switching was comparable across the three groups of participants. No difference between switch and repeat trials indicates that motor preparation levels were not affected by switch and repeat conditions, which was consistent with the findings in 
Gajewski and Falkenstein (2015). These results further support the notion that the CNV appears to be not an important neural marker related to the executive functions in the proactive control process. The years of professional motor skill practices is a significant covariate for $\mathrm{CNV}$ component, which suggests that participants with professional motor skill practices, regardless of any type of motor skills, had more negative-going CNV than those without professional motor skill practices. These findings were in line with those reported by Bianco et al. (2017a,b). The tonic activity in motor preparation was related to speed control in pre-supplementary motor area (Bianco et al., 2017a). In the present study, the speed requirement in both open (badminton) and closed (most were runners) skills was high, which may contribute to no group differentiation in CNV amplitude.

\section{Reactive Control and Motor Skill Experiences}

The open- and closed-skilled participants showed less positivegoing parietal stimulus-locked $\mathrm{P} 3$ in the switch than repeat trials in the non-predictive condition. Less positivity in the switch than repeat trials could not be found in the control group, who reported having no habit of practicing any types of physical activities. The results indicate that fewer attentional resources would have been deployed by the participants in updating the action rule in reactive control for switching in both open- and closed-skilled groups than in the control group. No significant differences were shown between these two motor-skilled groups, however. The comparable performance in stimulus-locked P3 for the open- and closed-skilled groups was not in line with our hypothesis, but was partly consistent with the findings in Wang et al.'s (2017). The findings of Wang and colleagues study revealed that open- and closed-skilled participants had comparable frontal $\mathrm{N} 2$ component and theta power for reactive control in a flanker task. The open-skilled participants, however, showed greater theta phase coherence $(0-500 \mathrm{~ms}, 4 \mathrm{~Hz} ; 300-400 \mathrm{~ms}, 5 \mathrm{~Hz})$ for incongruent trials compared to congruent trials, but this effect could not be found in the closed-skilled group. These findings suggested that the dissociation between open- and closed-skilled participants appears to be the stability level of neural process rather than the level of allocated cognitive resources. Compared with those engaged in closed motor skills, the open motor skills required the participants to give a response within a limited time (Jin et al., 2011). Thus, the superior performance in reactive control of open-skilled participants could be showed in the paradigm with short interval between the response and the next target stimulus, like $500 \mathrm{~ms}$ in Tsai and Wang's (2015), but not long interval between the response and the next target stimulus, like $2500 \mathrm{~ms}$ in the present study.

The behavioral results reported in Yu et al. (2017) indicated that open- and closed-skilled participants had significantly smaller switch cost of response times than controls. The ERP findings reported in this study reveal that both open-and closedskilled groups had higher efficiency in updating the new action rule in reactive control, reflected by less positive-going stimuluslocked P3. These findings were supported by those reported in the previous studies (Kamijo and Takeda, 2010; Zhang et al., 2015).
Kamijo and Takeda (2010) reported that the participants with regular physical training showed less switch cost and less positive stimulus-locked P3 in the switch than repeat trials than the sedentary controls, suggesting better reactive control in task switching. One plausible reason to account for the enhanced reactive control among the participants could have been the inevitable gains in cardiorespiratory fitness due to the intensive training received by both open- and close-skilled groups (Scisco et al., 2008; Tsai and Wang, 2015). Zhang et al. (2015) indicated that experienced fencers deployed less cognitive effort in the reactive inhibition process (as reflected from the less positivegoing P3 in Nogo condition) than their novice counterparts, which is consistent with the results revealed in this study. Nevertheless, Yamashiro et al. (2015) revealed more positive somatosensory Nogo-P3 in the open-skilled participants for reactive control in the Go/Nogo task than the closed-skilled participants. The inconsistent findings reported in Yamashiro et al. (2015) study were likely due to a lack of controlling the years of professional motor skill practices among the participants, which could confound the results in the reactive control condition. Another reason may be that the superior performance in baseball group resulting from the baseball specific training, which could not be generalized to the closed-skilled participants.

Significant correlations were revealed between the amplitudes of stimulus-locked P3 and the switch cost of response time only in the control group. The results are unexpected, as significant correlations were anticipated among the open- and closed-skilled participants. A plausible explanation for the non-significant findings could be due to the heterogeneity of the strategies employed by the open- or closed-skilled participants. To further test this proposition, a median-split method (Tamura et al., 2010) was applied to subdivide the open- and closed-skilled groups into higher and lower ability subgroups based on the participants' performances on between-trial difference in the stimulus-locked $\mathrm{P} 3$ amplitudes $\left(\mathrm{sP} 3_{\mathrm{S}}-\mathrm{sP} 3_{\mathrm{R}}\right)$. Significant correlations were found in the higher but not the lower open-skilled ability subgroups; whilst significant correlations but opposite in direction were found in both the higher and lower closed-skilled ability subgroups. The small sample size for each of the subgroups $(n=9)$ only allowed us to suspect within-group heterogeneity as a possibly confounding factor to the non-significant relationships between the ERP and behavioral results. Future studies should explore possible deployment of different strategies by the participants in the same open- or closed-skilled group and the differences in the neural processes associated with proactive or reactive controls.

Our negative-going frontal N2 findings in the switch than repeat trials (in the 100 validity) at the $\mathrm{Fz}, \mathrm{Cz}$, and $\mathrm{Pz}$ electrodes are consistent with those reported by Hsieh and $\mathrm{Wu}$ (2011). The results suggested the possible involvement of response-set switching and suppression of conflict response processes unique to the behavioral task used in this study (Nakamoto and Mori, 2008; Wang et al., 2017), as no significant group difference was revealed in the $\mathrm{N} 2$ among all the participant groups.

\section{Limitations}

First, the proactive and reactive control processes were prescribed by the switching task employed in this study. The results may 
not be directly generalized to other executive functions, such as inhibition or self-regulation. Second, the sample sizes of the open- and closed-skilled participants of this study were relatively small, which could have lowered the power of the analyses. Readers should be cautious when interpreting the results. Third, it is unclear whether badminton and track and field can best represent open- and closed-skilled physical activities, respectively. Any generalization of the findings should be restricted to participants of the same type of physical activities and level of competence. Future studies may consider recruiting participants of other types of physical activities and levels of competence. Fourth, the participants in the control group were those who had not been engaged in professional or amateur sports. The levels of physical activity engaged by these participants were not controlled. The existing differences between the open/closed-skilled and control groups could have been confounded by the differences in other parameters such as the levels of physical fitness rather than the types of motor skills, in case that the majority of the participants in the control group had been leading a sedentary lifestyle. Future study should recruit individuals who have comparable levels of physical fitness and/or physical training, but not at the professional level, as the control group. Fifth, the proposition of potential heterogeneity in strategies taken by the open- and closed-skilled groups was based on small sample sizes and without triangulation. Future studies should employ a more stringent research design and a larger sample size to address this issue.

\section{CONCLUSION}

This study explored how experiences in open and closed motor skills modulate individuals' proactive and reactive control processes. Compared with closed-skilled experiences, intensive open-skilled experiences were related to better proactive control for task switching characterized by lower switch cost and significant difference between switch and repeat trials of cuelocked P3 amplitudes. The enhanced proactive control is likely the result of high demand of anticipating environmental changes in open-skilled physical activities. Intensive open- and closedskilled experiences were related to better reactive control for task switching than the experiences of control participants, which

\section{REFERENCES}

Abreu, A. M., Macaluso, E., Azevedo, R. T., Cesari, P., Urgesi, C., and Aglioti, S. M. (2012). Action anticipation beyond the action observation network: a functional magnetic resonance imaging study in expert basketball players. Eur. J. Neurosci. 35, 1646-1654. doi: 10.1111/j.1460-9568.2012.08104.x

Babiloni, C., Marzano, N., Infarinato, F., Iacoboni, M., Rizza, G., Aschieri, P., et al. (2010). "Neural efficiency" of experts' brain during judgment of actions: a highresolution EEG study in elite and amateur karate athletes. Behav. Brain Res. 207, 466-475. doi: 10.1016/j.bbr.2009.10.034

Bertollo, M., Di Fronso, S., Filho, E., Conforto, S., Schmid, M., Bortoli, L., et al. (2016). Proficient brain for optimal performance: the MAP model perspective. PeerJ 4:e2082. doi: 10.7717/peerj.2082

Bianco, V., Berchicci, M., Perri, R. L., Quinzi, F., and Di Russo, F. (2017a). Exerciserelated cognitive effects on sensory-motor control in athletes and drummers was most likely resulted from higher cardiorespiratory fitness. Proactive and reactive controls as part of the process of motorskill development seem to be transferable to domain-general executive functions.

\section{DATA AVAILABILITY STATEMENT}

The datasets generated for this study are available on request to the corresponding author.

\section{ETHICS STATEMENT}

The studies involving human participants were reviewed and approved by The Research Grant Committee of the Hong Kong Polytechnic University. The patients/participants provided their written informed consent to participate in this study.

\section{AUTHOR CONTRIBUTIONS}

$\mathrm{AW}$ and $\mathrm{BL}$ contributed to the data interpretation and article writing. $\mathrm{BC}$ contributed to the conceptualization, data interpretation, and article writing. CC contributed to the conceptualization, study design, data interpretation, and article writing. JP contributed to the data collection, data analysis, and data interpretation. QY contributed to conceptualization, study design, data collection, data analysis, data interpretation, and article writing.

\section{FUNDING}

This work was supported by the General Research Fund of the Research Grant Council of Hong Kong (grant number 151044).

\section{ACKNOWLEDGMENTS}

The authors thank the University Research Facility in Behavioral and Systems Neuroscience for its support in providing the equipment and research personnel.

compared to non-athletes and other musicians. Neuroscience 360, 39-47. doi: 10.1016/j.neuroscience.2017.07.059

Bianco, V., Di Russo, F., Perri, R. L., and Berchicci, M. (2017b). Different proactive and reactive action control in fencers' and boxers' brain. Neuroscience 343, 260-268. doi: 10.1016/j.neuroscience.2016.12.006

Braver, T. S. (2012). The variable nature of cognitive control: a dual mechanisms framework. Trends Cogn. Sci. 16, 106-113. doi: 10.1016/j.tics.2011.12.010

Chan, J. S., Wong, A. C., Liu, Y., Yu, J., and Yan, J. H. (2011). Fencing expertise and physical fitness enhance action inhibition. Psychol. Sport Exerc. 12, 509-514. doi: 10.1016/j.psychsport.2011.04.006

Chevalier, N., Martis, S. B., Curran, T., and Munakata, Y. (2015). Metacognitive processes in executive control development: the case of reactive and proactive control. J. Cogn. Neurosci. 27, 1125-1136. doi: 10.1162/jocn_a_00782

Funderud, I., Lovstad, M., Lindgren, M., Endestad, T., Due-Tonnessen, P., Meling, T. R., et al. (2013). Preparatory attention after lesions to the lateral or orbital 
prefrontal cortex-an event-related potentials study. Brain Res. 1527, 174-188. doi: 10.1016/j.brainres.2013.06.017

Gajewski, P. D., and Falkenstein, M. (2011). Diversity of the P3 in the taskswitching paradigm. Brain Res. 1411, 87-97. doi: 10.1016/j.brainres.2011. 07.010

Gajewski, P. D., and Falkenstein, M. (2015). Lifelong physical activity and executive functions in older age assessed by memory based task switching. Neuropsychologia 73, 195-207. doi: 10.1016/j.neuropsychologia.2015.04.031

Grane, V. A., Brunner, J. F., Endestad, T., Aasen, I. E., Kropotov, J., Knight, R. T., et al. (2016). ERP correlates of proactive and reactive cognitive control in treatment-naive adult ADHD. PLoS One 11:e0159833. doi: 10.1371/journal. pone. 0159833

Hillman, C. H., Kramer, A. F., Belopolsky, A. V., and Smith, D. P. (2006). A cross-sectional examination of age and physical activity on performance and event-related brain potentials in a task switching paradigm. Int. J. Psychophysiol. 59, 30-39. doi: 10.1016/j.ijpsycho.2005.04.009

Hsieh, S., and Wu, M. (2011). Electrophysiological correlates of preparation and implementation for different types of task shifts. Brain Res. 1423, 41-52. doi: 10.1016/j.brainres.2011.09.018

Jamadar, S., Hughes, M., Fulham, W. R., Michie, P. T., and Karayanidis, F. (2010). The spatial and temporal dynamics of anticipatory preparation and response inhibition in task-switching. Neuroimage 51, 432-449. doi: 10.1016/ j.neuroimage.2010.01.090

Jin, H., Xu, G., Zhang, J. X., Gao, H., Ye, Z., Wang, P., et al. (2011). Event-related potential effects of superior action anticipation in professional badminton players. Neurosci. Lett. 492, 139-144. doi: 10.1016/j.neulet.2011.01.074

Kamijo, K., and Takeda, Y. (2010). Regular physical activity improves executive function during task switching in young adults. Int. J. Psychophysiol. 75, 304311. doi: 10.1016/j.ijpsycho.2010.01.002

Kida, N., Oda, S., and Matsumura, M. (2005). Intensive baseball practice improves the Go/Nogo reaction time, but not the simple reaction time. Cogn. Brain Res. 22, 257-264. doi: 10.1016/j.cogbrainres.2004.09.003

Li, L., Wang, M., Zhao, Q. J., and Fogelson, N. (2012). Neural mechanisms underlying the cost of task switching: an ERP study. PLoS One 7:e42233. doi: 10.1371/journal.pone. 0042233

Linssen, A. M., Sambeth, A., Riedel, W. J., and Vuurman, E. F. (2013). Higher, faster, stronger: the effect of dynamic stimuli on response preparation and CNV amplitude. Behav. Brain Res. 237, 308-312. doi: 10.1016/j.bbr.2012.09.050

Mcrobert, A. P., Ward, P., Eccles, D. W., and Williams, A. M. (2011). The effect of manipulating context-specific information on perceptual-cognitive processes during a simulated anticipation task. Br. J. Psychol. 102, 519-534. doi: 10.1111/ j.2044-8295.2010.02013.x

Müller, S., and Abernethy, B. (2012). Expert anticipatory skill in striking sports: a review and a model. Res. Q. Exerc. Sport 83, 175-187. doi: 10.5641/ 027013612800745059

Nakamoto, H., and Mori, S. (2008). Effects of stimulus-response compatibility in mediating expert performance in baseball players. Brain Res. 1189, 179-188. doi: 10.1016/j.brainres.2007.10.096

Nakamoto, H., and Mori, S. (2012). Experts in fast-ball sports reduce anticipation timing cost by developing inhibitory control. Brain Cogn. 80, 23-32. doi: 10. 1016/j.bandc.2012.04.004

Nicholson, R., Karayanidis, F., Bumak, E., Poboka, D., and Michie, P. T. (2006). ERPs dissociate the effects of switching task sets and task cues. Brain Res. 1095, 107-123. doi: 10.1016/j.brainres.2006.04.016

Rushworth, M. F., Passingham, R. E., and Nobre, A. C. (2002). Components of switching intentional set. J. Cogn. Neurosci. 14, 1139-1150. doi: 10.1162/ 089892902760807159

Scheibe, C., Schubert, R., Sommer, W., and Heekeren, H. R. (2009). Electrophysiological evidence for the effect of prior probability on response preparation. Psychophysiology 46, 758-770. doi: 10.1111/j.1469-8986.2009.00825.x

Scisco, J. L., Leynes, P. A., and Kang, J. (2008). Cardiovascular fitness and executive control during task-switching: an ERP study. Int. J. Psychophysiol. 69, 52-60. doi: 10.1016/j.ijpsycho.2008.02.009
Swainson, R., Jackson, S. R., and Jackson, G. M. (2006). Using advance information in dynamic cognitive control: an ERP study of task-switching. Brain Res. 1105, 61-72. doi: 10.1016/j.brainres.2006.02.027

Taddei, F., Bultrini, A., Spinelli, D., and Di Russo, F. (2012). Neural correlates of attentional and executive processing in middle-age fencers. Med. Sci. Sports Exerc. 44, 1057-1066. doi: 10.1249/MSS.0b013e31824529c2

Tamura, R., Kitamura, H., Endo, T., Hasegawa, N., and Someya, T. (2010). Reduced thalamic volume observed across different subgroups of autism spectrum disorders. Psychiatry Res. 184, 186-188. doi: 10.1016/j.pscychresns.2010.07.001

Tarantino, V., Mazzonetto, I., and Vallesi, A. (2016). Electrophysiological correlates of the cognitive control processes underpinning mixing and switching costs. Brain Res. 1646, 160-173. doi: 10.1016/j.brainres.2016.05.048

Tsai, C. L., and Wang, W. L. (2015). Exercise-mode-related changes in taskswitching performance in the elderly. Front. Behav. Neurosci. 9:56. doi: 10.3389/ fnbeh.2015.00056

Verburgh, L., Scherder, E. J., Van Lange, P. A., and Oosterlaan, J. (2014). Executive functioning in highly talented soccer players. PLoS One 9:e91254. doi: 10.1371/ journal.pone.0091254

Voss, M. W., Kramer, A. F., Basak, C., Prakash, R. S., and Roberts, B. (2010). Are expert athletes 'expert'in the cognitive laboratory? A meta-analytic review of cognition and sport expertise. Appl. Cogn. Psychol. 24, 812-826. doi: 10.1002/ acp. 1588

Wang, C. H., Chang, C. C., Liang, Y. M., Shih, C. M., Chiu, W. S., Tseng, P., et al. (2013a). Open vs. closed skill sports and the modulation of inhibitory control. PLoS One 8:e55773. doi: 10.1371/journal.pone.0055773

Wang, C. H., Chang, C. C., Liang, Y. M., Shih, C. M., Muggleton, N. G., and Juan, C. H. (2013b). Temporal preparation in athletes: a comparison of tennis players and swimmers with sedentary controls. J. Motor Behav. 45, 55-63. doi: $10.1080 / 00222895.2012 .740522$

Wang, C. H., and Tu, K. C. (2017). Neural correlates of expert behavior during a domain-specific attentional cueing task in badminton players. J. Sport Exerc. Psychol. 39, 209-221. doi: 10.1123/jsep.2016-0335

Wang, C. H., Yang, C. T., Moreau, D., and Muggleton, N. G. (2017). Motor expertise modulates neural oscillations and temporal dynamics of cognitive control. Neuroimage 158, 260-270. doi: 10.1016/j.neuroimage.2017.07.009

West, R., Bailey, K., Tiernan, B. N., Boonsuk, W., and Gilbert, S. (2012). The temporal dynamics of medial and lateral frontal neural activity related to proactive cognitive control. Neuropsychologia 50, 3450-3460. doi: 10.1016/j. neuropsychologia.2012.10.011

Yamashiro, K., Sato, D., Onishi, H., Sugawara, K., Nakazawa, S., Shimojo, H., et al. (2015). Skill-specific changes in somatosensory nogo potentials in baseball players. PLoS One 10:e0142581. doi: 10.1371/journal.pone.0142581

Yu, Q., Chan, C. C. H., Chau, B., and Fu, A. S. N. (2017). Motor skill experience modulates executive control for task switching. Acta Psychol. 180, 88-97. doi: 10.1016/j.actpsy.2017.08.013

Yu, Q., Fu, A. S. N., Kho, A., Li, J., Sun, X.-H., and Chan, C. C. H. (2016). Imagery perspective among young athletes: differentiation between external and internal visual imagery. J. Sport Health Sci. 5, 211-218. doi: 10.1016/j.jshs.2014. 12.008

Zhang, D., Ding, H., Wang, X., Qi, C., and Luo, Y. (2015). Enhanced response inhibition in experienced fencers. Sci. Rep. 5:16282. doi: 10.1038/srep1 6282

Conflict of Interest: The authors declare that the research was conducted in the absence of any commercial or financial relationships that could be construed as a potential conflict of interest.

Copyright $\odot 2019$ Yu, Chau, Lam, Wong, Peng and Chan. This is an open-access article distributed under the terms of the Creative Commons Attribution License (CC BY). The use, distribution or reproduction in other forums is permitted, provided the original author(s) and the copyright owner(s) are credited and that the original publication in this journal is cited, in accordance with accepted academic practice. No use, distribution or reproduction is permitted which does not comply with these terms. 